\title{
Water Economy Through Matching Plant Root Elongation to Mediterranean Landscapes
}

\author{
Chysanthi Chimona, Sophia Rhizopoulou
}

\begin{abstract}
Young plants of Ceratonia siliqua L., Myrtus communis L., Nerium oleander L., Rosmarinus officinalis L., Ligustrum japonicum Thunb. and Pittosporum tobira (Thunb.) Aiton were grown in long tubes as well in rhizotrons. After a period of acclimation to the conditions of the experimental construction under normal watering conditions, some plants were watered whereas other plants remained unwatered for a period of one month. During the studying period the plants have been observed and regular measurements of roots and above ground parts development were taken. The results show the resistance of the Mediterranean plants $(C$. siliqua, $M$. communis, $N$. oleander) to water deficit in comparison to plants that are often used in parks and urban horticulture ( $L$. japonicum, $P$. tobira), whereas $R$. officinalis shows an intermediate stage of endurance to drought.
\end{abstract}

Index Terms-landscaping, plants, roots, water status.

\section{INTRODUCTION}

There is a growing need for green spots in Mediterranean cities. The Mediterranean urban environment consists of elevated temperatures and low precipitation in addition to the lack of natural and/or planted places that could anticipate these conditions during summer. Citizens need green urban landscapes that improve their quality of life [1]. The native evergreen sclerophyll vegetation, which is subjected to prolonged periods of soil drying, maintains its capacity to reproduce, grow and survive [2], [3] under abiotic stress.

Plants that develop long, tap root systems are able for water uptake from lower ground levels and therefore irrigation can be avoided. It has been argued that roots grow as shallow as possible and as deep as necessary, in response to the required water supply [4], [5]. An increasing number of studies clearly indicate that "looking deeper" is essential in order to increase our understanding about plant water status at various scales, from the rhizosphere to the above-ground tissue level.

The evergreen plant habit is achieved through an extended leaf life span, which allows the tissues to be photosynthetically active for a prolonged period. An extended leaf lifespan ensures photosynthetic carbon gain for the amount of nutrients invested in construction and adaptive shift in biomass allocation. Ceratonia siliqua (carob tree) is a slowly growing, woody evergreen sclerophyll species,

Chrysanthi Chimona, Department of Botany, Faculty of Biology National and Kapodistrian University of Athens, Athens, Greece

Sophia Rhizopoulou, Department of Botany, Faculty of Biology National and Kapodistrian University of Athens, Athens, Greece

The study is funded by IKY FELLOWSHIPS OF EXCELLENCE FOR POSTGRADUATE STUDIES IN GREECE - SIEMENS PROGRAM. widespread as a native plant in the Mediterranean Basin; it is also distributed in Arabia and Oman, and has been introduced in California, Mexico and Southern Australia [6]. C. siliqua is considered a phylogenetically primitive species of tropical origin that has been cultivated in the Mediterranean area since historic times; it is an important economic plant [7], which has been used for afforestation in semi-arid regions [8]. It appears that the slowly growing Mediterranean evergreen $C$. siliqua possess features that confer a substantially efficient development in drier sites, in comparison to the widespread Rosmarinus officinalis (rosemary) [9] and Myrtus communis (myrtle) with aromatic leaves, and Nerium oleander (oleander) that withstand abiotic stresses, such as drought, heat, wind and salt spraying, but the foliage is severely injured by freezing temperatures [10], [11]. The relatively more rapidly growing Ligustrum japonicum (Japanese privet) and Pittosporum tobira (Japanese Pittosporum) are native to the Far East and introduced as ornamental evergreens in the Mediterranean region [12], [13].

\section{Materials AND MethodS}

\section{A. Tubes}

Plastic tubes $1 \mathrm{~m}$ long were cut in two pieces along the main axis and their initial cylindrical shape was (re)maintained with insulating tape. The tubes were filled with common, non-enriched soil and a young plant of each species was potted in each tube [14]. Then, we transferred the tubes into a growth chamber, at $25 \pm 1{ }^{\circ} \mathrm{C}, 50 \%$ relative humidity and $16 \mathrm{~h}$ photoperiod $\left(500 \mu \mathrm{mol} \mathrm{m}^{-2} \mathrm{~s}^{-1} \mathrm{PAR}\right)$. In the beginning, all the considered plants were well watered in order to be acclimated to the tubes. Then, five randomly selected plants from each of the studied species were subjected to controlled watering (watered tubes), whereas five other plants from each species received no water (unwatered tubes). At intervals of 5 days during the experimental treatment, the tubes were carefully opened and the root length was measured, as well as the shoot length; also soil was sampled for determination of soil water content. This experimental process allows the realization of non-destructive sampling and measurements.

\section{B. Rhizotrons}

The rhizotron, which can be a modified form of an underground unit that facilitates root growth studies and/or a constructed root observation chamber designed to allow repeated observation and sampling of roots and soil [15], [16], remind us that "art imitates nature"; this is a well known 
Aristotelian catchphrase. According to Aristotle, nature is considered as the primary material out of which any natural object is made and contrasts the processes of art with those of nature by calling them "makings". Therefore, rhizotrons are promising for laboratory studies involving relatively small soil volumes and in situ observations of deep roots [17], [18]. Furthermore, sampling depths are often decided arbitrarily and set to values that are too shallow to allow reliable estimates of rooting depth, under field conditions. Despite technological advances and introduced innovations [19], [20], the study of deep roots and their rhizospheres remains inherently time-consuming, technically demanding and costly. Knowledge of adaptations improving the acquisition of water resources in natural ecosystems may be useful for sustainable agriculture in the future [21], [22]. Therefore, the root elongation of plants could be continuously observed under different watering conditions, without destroying the specimens throughout the study period.

\section{RESUlts AND DisCUSSION}

In Fig. 1 normalized values of root elongation of the studied plants under watering and unwatering conditions can be seen, during the study. The results show continued elongation of roots, preceding the Mediterranean plants (carob, oleander, and myrtle) followed by rosemary and last, by Japanese privet and Japanese pittosporum.

In Fig. 2 normalized values of the above ground parts development can be seen, during the study. Most unwatered plants cease the development of the above ground parts in comparison to the development of their root. Carob tree and oleander showed a small elongation of their shoot at the last 10 days of the studying period.

The results of the study show rapid acclimation of the Mediterranean plants to drought conditions. The response of carob, oleander and myrtle to water deficit is indicated by their root elongation 15 days after the beginning of the drought simulation experiment. In the case of rosemary shrubs, with aromatic leaves, more time than 15 days is required in order to compensate water shortage; its roots developed towards more watered soil horizons, but in a slower rate in comparison to carob tree. The considered plant species responded to the dry soil by postponing the above ground parts development and contributing energy to the elongation of the below ground system that absorbs water.

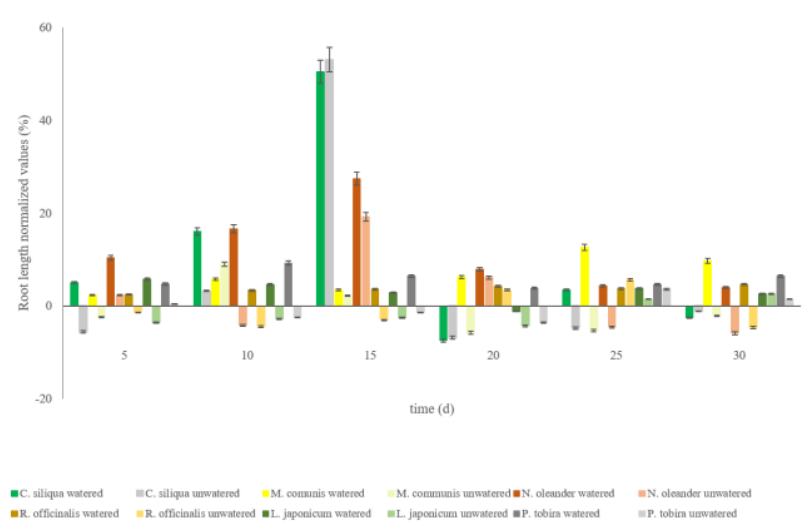

Fig. 1. The histogram shows normalized values of root elongation; mean values (N: 5) and S.E. $(p \leq 0.05)$.

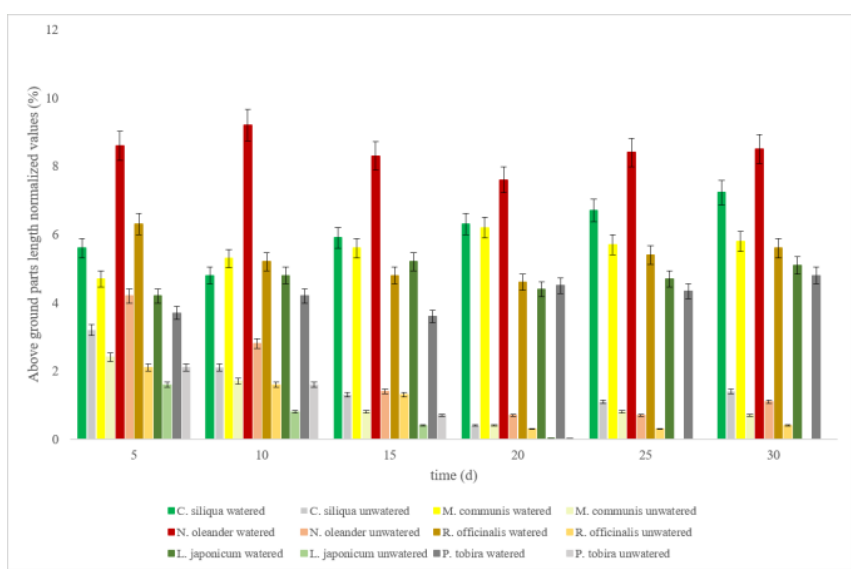

Fig. 2. The histogram shows normalized values of the length of above ground parts; mean values (N: 5) and S.E. $(p \leq 0.05)$.

\section{CONCLUSIONS}

Plants, through photosynthesis and gas exchange contribute to alterations of concentrations of air pollutants, and provide water vapor to the atmosphere through transpiration. The greening of urban landscapes, parks and domestic gardens can be enhanced with the appropriate plant distribution and management, via seasonal planting patterns of drought resistant shrubs [23]. Urban landscapes in Mediterranean environments may be reconsidered and designed using plant species typical of the Mediterranean ecosystems; such species can be either native or endemic and usually consist of tap root systems capable for water uptake from deep soil horizons.

\section{REFERENCES}

[1] W. Elmendorf, "The importance of trees and nature in community: A review of the relative literature". Arboriculture and Urban Forestry, vol. 34, 2008, pp. 152-156.

[2] W.D. Bowman, S.W. Roberts, "Seasonal and diurnal water relations adjustments in three evergreen chaparral shrubs", Ecology, vol. 66(3), 1985, pp.738-742.

[3] P. Baltzoi, K. Fotia, D. Kyrkas, K. Nikolaou, A.T. Paraskevopoulou, A.R. Accogli, G. Karras, "Low water demand plants for landscaping and agricultural cultivations - a review regarding local species of Epirus/Greece and Apulia/Italy”, Procedia, vol. 4, 2015, pp: 250-260.

[4] H.J. Schenk, R.B. Jackson, "Mapping the global distribution of deep roots in relation to climate and soil characteristics", Geoderma, vol. 126, 2005, pp. 129-140.

[5] S. Rhizopoulou, G. Kapolas, "In situ study of deep roots of Capparis spinosa L. during the dry season: evidence from a natural "rhizotron" in the ancient catacombs of Milos Island (Greece)", Journal of Arid Environments, vol. 119, 2015, pp. 27-30.

[6] L. Ramon-Laca, D.J. Mabberley, "The ecological status of the carob-tree (Ceratonia siliqua, Leguminosae) in the Mediterranean", Botanical Journal of the Linnean Society, vol. 144, 2004, pp. 431-436.

[7] B. Biner, H. Gubbuk, M. Karhan, M. Aksu, M. Pekmezci, "Sugar profiles of the pods of cultivated and wild types of carob bean (Ceratonia siliqua L.) in Turkey", Food Chemistry, vol. 100, 2007, pp. 1453-1455.

[8] F. Catarino, "The carob tree: an exemplary plant", Naturopa, vol. 73, 1993, pp.14-15.

[9] R. Ribeiro-Santos, D. Carvalho-Costa, C. Cavaleiro, H.S. Costa, T.G. Albuquerque, M.C. Castilho et al, "A novel insight on an ancient aromatic plant: The rosemary (Rosmarinus officinalis L.)", Trends in Food Science \& Technology, vol. 45(2), 2015, pp. 355-368.

[10] M.S. Meletiou-Christou, G.P. Banilas, C. Bardis, S. Rhizopoulou, "Plant biomonitoring: impact of urban environment on seasonal dynamics of storage substances and chlorophylls of oleander", Global Nest Journal, vol. 13, 2011, pp. 393-404.

[11] M.S. Meletiou-Christou, S. Rhizopoulou, "Constraints of photosynthetic performance and water status of four evergreen species 
World Journal of Research and Review (WJRR)

ISSN:2455-3956, Volume-5, Issue-2, August 2017 Pages 22-24

co-occuring under field conditions", Botanical Studies, vol. 53, 2012, pp.325-334.

[12] Z. ZunLing, H. Wei, Z.GuangNing, "Comparison and evaluation of improvement model of forest form for landscape and environmental protection in urban forest park: taking Laoshan National Forest Park as an example", Journal of Plant Resources and Environment, vol. 20, 2011, pp.89-94.

[13] M.S. Meletiou-Christou, S. Rhizopoulou, "Leaf functional traits of four evergreen species growing in Mediterranean environmental conditions", Acta Physiologiae Plantarum, vol. 39(1), 2017, pp. 34.

[14] R.E. Sharp, W.J. Davies, "Root growth and water uptake by maize plants in drying soil", Journal of Experimental Botany, vol. 36(9), 1985, pp. 1441-1456.

[15] R.S. Hilton, D.S. Bhar, G.F. Mason, “A rhizotron for in situ root growth studies", Canadian Journal of Plant Science, vol. 49, 1969, pp. 101-104.

[16] M.G. Huck, H.M. Taylor, "The rhizotron as a tool for root research", Advances in Agronomy, vol. 35, 1982, pp. 1-35.

[17] B.R. James, R.J. Bartlett, J.F. Amadon, "A root observation and sampling chamber (rhizotron) for pot studies”, Plant Soil, vol. 85, 1985 pp. 291-293.

[18] J. Lussenhop, R Fogel, "Observing soil biota in situ", Geoderma, vol. 56, 1993, pp. 25-36.

[19] K. Hill, S. Porco, G. Lobet, S. Zappala, S. Mooney, X. Draye, et al, "Root Systems Biology: integrative modeling across scales, from gene regulatory networks to the rhizosphere". Plant Physiology, vol. 163, 2013, pp. 1487-1503.

[20] J.L. Maeght, B. Rewald, A. Pierret, "How to study deep roots - and why it matters", Frontiers in Plant Science, vol. 4, 2013, pp. 299.

[21] J. Passioura, "Increasing crop productivity when water is scarce - from breeding to field management", Agricultural Water Management, vol. 80, 2006, pp. 176-196.

[22] A.P. Whitmore, R.W. Whalley, "Physical effects of soil drying on roots and crop growth", Journal of Experimental Botany, vol. 60, 2009, pp 2845-2857.

[23] G. Filibeck, P. Petrella, P. Cornelini, “All ecosystems look messy, but some more so than others: A case-study on the management and acceptance of Mediterranean urban grasslands". Urban Forestry \& Urban Greening, vol. 15, 2016, pp. 32-39.

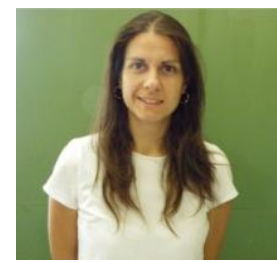

Chrysanthi Chimona has obtained her degree of Biology in the National and Kapodistrian University of Athens. She immediately continued as a Ph.D. student in the same University, which she obtained with a scholarship co-financed by the European Union (European Social Fund - ESF) and Greek national funds (Research Funding Program: Heracleitus II). Her Ph.D. thesis is entitled 'Biomimetics and Water Status of Plant Tissues'. During her Ph.D. studies she participated in the CAREX Summer School on Life in Extreme Environments, which was attended by 40 selected students. She has three published works in scientific peer reviewed journals and nine participations in scientific conferences. Her scientific work has been focused on plant physiology, flowers, surface structures and their properties, as well water relations and status of plant tissues. She is currently working on a post-Doctorate research about resistant to drought Mediterranean plants of urban landscapes. Her research is funded by IKY FELLOWSHIPS OF EXCELLENCE FOR POSTGRADUATE STUDIES IN GREECE SIEMENS PROGRAM.

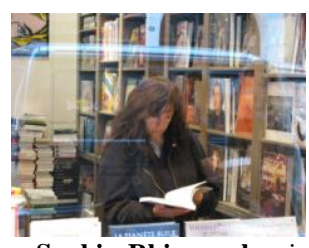

Sophia Rhizopoulou is Professor of Plant Environmental Physiology at the National and Kapodistrian University of Athens in Greece, Faculty of Biology and Department of Botany. Her research interests include plant environmental physiology, water relations, adaptations of Mediterranean plants, micro- and nano-sculpture of plants' surfaces, roots, wettability and living archives. Her research has been published in many books and articles.
She attended numerous national and international conferences and workshops. She supervised more than a hundred Diploma-, Master- and $\mathrm{PhD}$-Theses; for further details see information presented in http://publicationslist.org/sophia.rhizopoulou. 